\title{
When Do Organizations Behave Opportunistically? The Effects Of Collectivistic Organizational Culture
}

\author{
Sungmin Ryu, Ph.D, Sungkyunkwan University, South Korea \\ Woojung Jang, Doctoral Candidate, Sungkyunkwan University, South Korea \\ Jukyung Lee, MBA, Sungkyunkwan University, South Korea \\ Jong Eun Lee, Ph.D, Sungkyunkwan University, South Korea
}

\begin{abstract}
Transaction cost theory posits that firms behave opportunistically if they are given the chance. In reality, however, some firms act opportunistically, whereas others do not. This raises the question of under what circumstances firms tend to behave opportunistically. Previous studies provided no clear explanation of when opportunism occurs and what its antecedents are. This study identifies the circumstances under which firms behave opportunistically by empirically testing the following two causal factors in opportunistic behaviors: transaction-specific investment (TSI) and collectivistic organizational culture. The survey results indicate that a firm's TSI is an important factor influencing opportunistic behaviors and that collectivism moderates the relationship between TSI and opportunism.
\end{abstract}

Keywords: Opportunism; Transaction-Specific Investment; Collectivistic Organizational Culture

\section{INTRODUCTION}

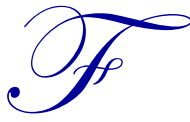

irms pursue their own interests unintentionally by cheating on their partners (Williamson, 1985). Because firms have their own goals, they have a good reason to behave opportunistically to achieve their goals. However, opportunism, a self-interest-seeking behavior based on guile (Williamson, 1975), does not always occur. Some firms act opportunistically, whereas others trust their partners and build cooperative relationships with them. Thus, it is difficult to determine opportunistic actors ex ante (John, 1984; Rindfleisch \& Heide, 1997; Barney, 1990).

This raises the question of under what circumstances firms tend to behave opportunistically. A number of studies have investigated firms' opportunistic behaviors. For example, when a firm's partner makes a transactionspecific investment (TSI), then the firm is likely to behave opportunistically only for its own interests (Heide \& John, 1992; Doney \& Cannon, 1997; Brown, Dev \& Lee, 2000). TSI refers to the transfer of assets that support a given transaction (Williamson, 1985). However, Bown, Dev, and Lee (2000) argued that there is no correlation between TSI and opportunism. Ghoshal and Moran (1996) suggested that opportunism is influenced by multiple factors because complex phenomena characterize inter-firm relationships. Thus, there may be some other factors that influence firms' opportunistic behavior.

Here the question of interest is what factors are likely to influence opportunistic behaviors. We propose and empirically test two causal factors in opportunistic behaviors: TSI and the collectivistic organizational culture (COC).

The purpose of this study is to clarify the conditions under which firms behave opportunistically. Previous studies have investigated opportunism but provided no clear explanation of when opportunism occurs and when it does not. In this regard, we consider the COC and examine the moderating effects of the COC on the relationship between TSI and opportunistic behaviors. 
In the next section, we discuss the theoretical background for opportunism, TSI, and the COC from the manufacturer's perspective and present the research hypotheses. We then describe the study and its methodology, and in the final section, we discuss the results based on a sample of 115 purchasing managers from manufacturing firms.

\section{THEORETICAL BACKGROUND AND HYPOTHESES}

\section{Opportunism}

Transaction cost theory (TCT) posits that individuals are limited to bounded rationality and that opportunism may occur in any transaction (Williamson, 1985). Opportunism refers to "self-interest seeking with guile" (Williamson, 1975). Guile means "lying, stealing, cheating, and calculated efforts to mislead, distort, disguise, obfuscate, or otherwise confuse." (Williamson, 1985). Thus, a firm engaging in opportunism cheats its partner to gain profits.

Opportunism can take the following two forms: blatant opportunism and lawful opportunism. According to Williamson (1985), blatant opportunism manifests itself through both (1) intentional misrepresentations (passive opportunism during the initiation of a relationship) and (2) various forms of violations (active opportunism over the course of the relationship) (Wathne \& Heide, 2000)

Lawful opportunism is a type of violation that does not pertain to a formal contract (Williamson, 1991a). A lack of a detailed contract leaves loopholes by which a firm can avoid informally manifested obligations or engage in behaviors that unilaterally modify the provisions of the contract. That is, lawful opportunism is to seek selfinterest by ignoring obligations that are not stated clearly in a formal contract, and thus, it cannot be punished.

A form of active opportunism under lawful opportunism is the hold-up problem (Wathne \& Heide 2000), which can occur when one firm's TSI exceeds that of the other. A firm in a TSI-based relationship cannot withdraw from the relationship easily because it is likely to lose its investment if it does. In addition, the firm with a smaller TSI may exploit its partner's TSI position and behave opportunistically.

Williamson $(1975,1985)$ used the term "opportunism" for both opportunistic attitudes and opportunistic behaviors and thus did not distinguish between them. Ghoshal and Moran (1996) distinguished opportunistic attitudes from opportunistic behaviors and defined the former as the proclivity to behave opportunistically and the latter as specific self-interest-seeking behaviors based on guile. The present study focuses on opportunistic behaviors because even if an organization has opportunistic attitudes, it may not behave opportunistically.

TCT posits that individuals act opportunistically when they are given the chance (Rindfleisch \& Heide, 1997). However, opportunistic behaviors do not always occur (Ghoshal \& Moran 1996). Thus, the problem of opportunistic behavior is difficult to predict in terms of when it occurs and which factors stimulate it.

When does an organization behave opportunistically? Previous studies have investigated opportunism but provided no clear explanation of when it occurs and what its antecedents are.

\section{Transaction-Specific Investment}

In a partnership, firms invest a certain amount of their assets (Williamson, 1985). TSI targets not only specialized equipment and facilities but also human asset specificity (Anderson \& Weitz, 1986; Rindfleisch \& Heide, 1997; Brown, Dev \& Lee, 2000). TSI has little or no value outside the focal relationship (Williamson, 1985; Brown, Dev \& Lee, 2000).

According to Brown, Dev, and Lee (2000), firms engage in TSI for various reasons. First, TSI is more efficient and effective than generalized assets. For example, TSI is more likely to induce demand and reduce costs than generalized assets. Second, firms in a TSI-based relationship signal their honorable intentions toward the relationship (Mishra, Heide \& Cort 1998). Finally, TSI may be a precondition for a partnership effectiveness and 
efficiency. TSI can be required as a type of performance bond to be forfeited if a firm is found to behave opportunistically.

A firm's TSI is related to the firm's dependence on its partner. A firm's dependence on its partner refers to its need to maintain the relationship with the partner to achieve its goals (Frazier, 1983; Kumar, Scheer \& Steenkemp, 1995). According to power-dependence theory (Pfeffer \& Salancik, 1978), a firm's TSI may constrain its ability to acquire vertical control. When a firm enters a TSI-based relationship, its TSI has no value outside the relationship. Therefore, it is difficult for a firm to terminate the relationship because it may lose its TSI if it does so (Doney \& Cannon, 1997; Brown, Dev \& Lee, 2000). Thus, a firm with some TSI is concerned about discontinuing the relationship, which reduces its power over its partner. In turn, this can encourage the partner to exploit the situation and thus to behave opportunistically. In this regard, we propose the following hypothesis:

H1: The larger the TSI of a firm's partner, the more likely the firm is to behave opportunistically.

\section{Organizational Culture: Collectivism}

The relationship between firms is influenced by the social context of that economic relationship (Hill, 1990). One context is the organizational culture, which refers to a complex set of values, beliefs, assumptions, and symbols that influence the way firms conduct their business activity (Deal \& Kennedy, 1982; Peters \& Waterman, 1982; Barney, 1986). Louis (1983) asserted that a firm's culture not only defines its relevant employees but also determine how the firm influences its business partners such as customers and suppliers (Barney, 1986).

There are several elements of the organizational culture, including uncertainty avoidance, collectivism, and power distance (Hofstede, 2001). The present study investigates the effects of collectivism on opportunism because collectivism is the most robust concept among diverse cultural elements (Triandis, 1995).

Collectivism refers to the extent to which a firm believes that it should focus on collective goals instead of its private goals when working with its partners. Collectivists value the social fabric and group norms, whereas individualists desire to be independent of other firms (Steensma et al., 2000; Wuyts \& Geyskens, 2005).

Firms with a COC prefer group goals to their private goals (Wuyts \& Geyskens 2005). According to Hewett and Bearden (2001), the relationship between trust and cooperation is stronger for a high level of collectivism. Therefore, a firm with a COC is more likely to pursue a mutual goal in its relationship with a partner and thus is more likely to trust the partner.

Some studies have examined the effects of organizational cultures on opportunism (Williamson, 1993; Ghoshal \& Moran, 1996; Chen, Peng \& Saparito, 2002). Traditionally, researchers have insisted that individualists are more likely to be opportunistic than collectivists. However, Chen, Peng, and Saparito (2002) argued that both collectivists and individualists are likely to be opportunistic depending on relational facts. In this regard, although some studies have suggested that individualists are more likely to behave opportunistically, there exists no clear explanation of the circumstances under which opportunism occurs.

A collectivistic firm is likely to pursue mutual goals (Triandis, 1995). Thus, it is not likely to exploit TSI. In addition, collectivistic firms are more cooperative than individualistic ones and thus are more likely to share information with their partners. Therefore, although TSI may induce opportunistic behaviors (Rangan, Corey \& Cespedes, 1993; Ghoshal \& Moran, 1996; Rindfleisch \& Heide, 1997; Bown, Dev \& Lee, 2000), a highly collectivistic firm may successfully avoid such behaviors. In this regard, we propose the following hypothesis:

H2: Collectivism moderates the relationship between a firm's opportunistic behavior and its partner's TSI. 


\section{RESEARCH DESIGN}

\section{Context}

We selected a sample of Korean manufacturers to test the hypotheses about the effects of TSI and collectivism on the relationship between manufacturers and their suppliers. Because manufacturers depend on their suppliers for parts in the assembly of final products, there are substantial interactions between them, and this provides fertile opportunities for opportunistic behaviors (Gundlach \& Achrol, 1993).

\section{Sample and Data Collection}

We selected manufacturers through systematic random sampling from a mailing list of Samsung Engineering, a major engineering firm in Korea. We surveyed purchasing managers of Samsung Engineering's subcontractors who were suitable candidates for responding to items about their firms and transaction partners. Firsttier subcontractors completed products with components supplied by second-tier subcontractors and provided Samsung Engineering with finished products. By surveying first-tier subcontractors that had various relationships with their transaction partners (i.e., second-tier subcontractors), we examined their opportunistic behaviors.

We contacted the purchasing manager of each firm by telephone and mailed him or her a questionnaire. We selected the head of the purchasing department as the key respondent. Purchasing managers were responsible for securing materials from suppliers, and thus, we expected them to be knowledgeable about those materials and have close relationships with suppliers (Hutt \& Speh, 2000). After callbacks and a second mailing, we collected a total of 115 responses out of 520 delivered (a response rate of approximately 22\%).

\section{Non-Response Bias}

We checked for non-response bias in two ways. First, we compared early respondents with late ones (Armstrong \& Overton, 1977). In addition, we compared the mean values for each scale (i.e., TSI, collectivism, and opportunism) and the characteristics of the respondents and firms (i.e., years of the manufacturer-supplier relationship and years of experience as a purchasing manager in the firm) between the two groups. The results indicate no significant difference between the groups in terms of these scales and characteristics, implying that nonresponse bias was not a serious problem ( $\mathrm{p}$-values ranged from 0.33 to 0.57 ).

\section{Measurement}

We developed the measurement scale in two stages. First, we obtained existing measures of the focal variables from previous studies. Second, we conducted in-depth interviews with three purchasing managers to check the relevance of the collected measures. We revised the wording of some items based on the interview results. In addition, we hired two experts with a doctoral degree in marketing to evaluate the face validity of the items, and they both concluded that the items well reflected collectivism, opportunism, and TSI. All items were measured using a seven-point Likert-type scale ranging from "strongly agree" (7) to "strongly disagree" (1).

Opportunism refers to "self-interest seeking with guile" (Williamson, 1975), and guile has been defined as "lying, stealing, cheating, and calculated efforts to mislead, distort, disguise, obfuscate, or otherwise confuse" (Williamson, 1985) To measure opportunism, we used items adapted from John (1984). TSI refers to "the transferability of the assets that support a given transaction" (Williamson, 1985). We measured TSI by using an item from Ganesan (1994). Collectivism refers to the extent to which a firm believes that it should focus on collective goals instead of its private goals when working with a partner. Collectivistic firms value the social fabric and group norms, whereas individualistic ones desire to be independent of other firms (Steensma et al., 2000; Wuyts \& Geyskens, 2005). To measure collectivism, we used items from Wuyts and Geyskens (2005). 
Table 1

Reliability of Independent Variables

Opportunism $\mathrm{CR}=.71$

1. We sometimes alter facts slightly to get what we need.

2. We sometimes promise to do things without actually doing them later.

3. We sometimes hide facts to get what we need.

4. We sometimes deceive suppliers to get what we need.

Transaction-Specific Investment $\quad \mathrm{CR}=.72$

1. Suppliers tailor their merchandise and procedures to meet our specific needs.

2. It would be difficult for suppliers to recoup their investment if they switch to another partner. .65

3. Suppliers have dedicated large investments to their relationships with our firm.

4. Supplier would lose a substantial portion of their investment if it were to switch to another company.

Collectivism

$\mathrm{CR}=.76$

1. Our firm places great emphasis on teamwork among firms in our supply chain.

2. Close cooperation with firms in our supply chain is preferred to working independently.

3. Firms and their suppliers are always jointly responsible for the success and failure of their working relationships.

$\chi^{2}(32)=40.24(\mathrm{p}=.12), \mathrm{GFI}=.92 \mathrm{AGFI}=0.88, \mathrm{CFI}=.94, \mathrm{RMSEA}=.051$.

\section{Validity Analysis}

We conducted an exploratory factor analysis to verify the validity of the four measurement factors. In addition, we conducted a principal component analysis with Varimax rotation. According to the results, the total cumulative variance of the four measurement factors was $71.26 \%$ and significant. In addition, all rotation sums of squared loadings exceeded 0.5 , suggesting sufficient validity.

We considered the KMO (Kaiser-Meyer-Olkin) measure of sampling adequacy and conducted Bartlett's test of sphericity to check the acceptability of the data for the factor analysis. In general, data are considered acceptable when the KMO value is close to 1 and the significance probability is under 0.05 . According to the results, the KMO value was 0.738 , and Bartlett's significance probability was 0.000 , indicating that the data were fitted well.

\section{Reliability Analysis}

We assessed internal consistency by using Cronbach's alpha. According to the results, Cronbach's alpha for all factors exceeded 0.7, indicating sufficient internal consistency (Table 1). The correlation matrix is reported (Table 2).

Table 2

Correlation Matrix

\begin{tabular}{llcccc}
\hline & & & & \\
& & $\mathbf{2}$ & & $\mathbf{4}$ \\
\hline $\mathbf{1}$ & Opportunism & 1.000 & & & \\
$\mathbf{2}$ & TSI & 0.234 & 1.000 & & \\
$\mathbf{3}$ & Collectivism & -0.150 & 0.357 & 1.000 & \\
$\mathbf{4}$ & TSI X Collectivism & 0.075 & 0.883 & 0.747 & 1.000 \\
& Mean & 6.208 & 18.982 & 17.539 & 335.478 \\
& SD & 2.303 & 3.257 & 2.201 & 82.363 \\
\hline
\end{tabular}

\section{ANALYSIS AND RESULTS}

We examined the circumstances facilitating firms' opportunistic behaviors. We conducted a multiple regression analysis using SPSS 17.0 to test the hypotheses. 
The results provide support for Hypothesis $1(\beta=1.932, \mathrm{p}<0.01)$, indicating that a firm whose partner made a large TSI was more likely to behave opportunistically (Table 3 ).

Table 3 shows the results for the interaction effects of collectivism and TSI on opportunism. We expected that collectivistic firms and firms engaging in TSI would be less likely to behave opportunistically. As shown in Table 3, collectivism moderated the relationship between TSI and opportunism. That is, collectivistic firms did not behave opportunistically even when their partners engaged in TSI. Therefore, these results provide support for Hypothesis $2(\beta=-2.268, \mathrm{p}<0.05)$.

Table 3

Regression Results for Hypotheses

\begin{tabular}{|l|c|}
\hline & Dependent Variables \\
\hline Independent Vars. & Opportunism \\
\hline TSI & $1.932(2.609)^{\mathrm{b}}$ \\
\hline Collectivism & $.854(1.633)$ \\
\hline TSI*Collectivism & $-2.268(-2.181)^{\mathrm{a}}$ \\
\hline Adj. R-Squared & .124 \\
\hline
\end{tabular}

${ }^{\mathrm{a}}:$ Rejected Ho at $\mathrm{p}<.05$ (one-tailed test).

${ }^{\mathrm{b}}:$ Rejected Ho at $\mathrm{p}<.01$ (one-tailed test).

\section{CONCLUSIONS}

In this study, we examined firms' opportunism in a partnership. Previous studies have suggested that it is difficult to predict opportunistic behaviors ex ante (John, 1984; Rindfleisch \& Heide, 1997; Barney, 1990), and it remains unclear what factors induce opportunistic behaviors. We attempted to identify the factors influencing firms' opportunistic behaviors by investigating the moderating effects of the COC.

The results indicate that collectivistic firms were less likely to behave opportunistically even when their partners engaged in TSI. Although TSI had a negative effect on opportunism, collectivism moderated the effects of TSI on opportunism.

The results provide support for transaction cost theory (Williamson, 1975), which posits that TSI induces a hold-up problem because firms take opportunistic advantage of their partners' TSI.

This study extends transaction cost theory by verifying the conditions under which firms avoid opportunistic behaviors. Transaction cost theory does not consider other contexts that may influence firms' opportunistic behaviors. This study's results demonstrate that although TSI may induce opportunistic behaviors, collectivistic firms can avoid the tendency to behave opportunistically. Therefore, transaction cost theory can extend its explanation of firms' opportunistic behaviors by including the organizational culture as a main variable in its framework.

\section{LIMITATIONS AND FUTURE RESEARCH}

In this study, we selected the sample by considering subcontractors of Samsung Engineering. That is, we considered only the engineering industry to test the hypotheses, which limits the generalizability of the results because each industry has its own distinct characteristics. That is, the results may vary according to the industry considered. For this reason, future research should consider a wider range of industries.

Another limitation involves the individualistic organizational culture. We obtained the data from domestic firms in Korea. Although the business environment in Korea has changed in recent decades, Korean firms may be more collectivistic than their Western counterparts. In this regard, future research should test the hypotheses by using data from more individualistic countries such as the U.S. and the U.K.

Firms' opportunistic behaviors are influenced not only by interorganizational factors (e.g., TSI) and organizational factors (e.g., collectivism) but also by the national culture such as guanxi (Gu et al., 2008). Guanxi 
has been shown to influence firms' trust in their partners (Gu et al., 2008). Thus, the relational aspects of guanxi may have negative effects on opportunistic behaviors. In this regard, future research should determine the effects of guanxi and the interaction effects of guanxi and TSI/collectivism on opportunistic behaviors.

\section{AUTHOR INFORMATION}

Sungmin Ryu, Ph.D., School of Business, Sungkyunkwan University, South Korea. E-mail: smryu@ skku.edu

Woojung Jang, Doctoral Candidate, School of Business, Sungkyunkwan University, South Korea. E-mail: airwj@kdu.ac.kr

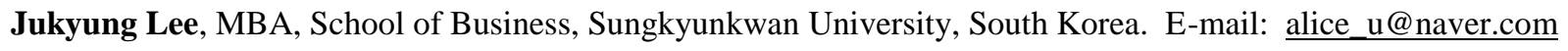

Jong Eun Lee, Ph.D., School of Business, Sungkyunkwan University, South Korea. E-mail: jelee2012@skku.edu (Corresponding author)

\section{REFERENCES}

1. Anderson, Erin and Barton A. Weitz (1986), "Make-or-Buy Decisions: Vertical Integration and Marketing Productivity," Sloan Management Review, 27, 3-19.

2. Anderson, Erin (1988), "Transaction Cost as Determinants of Opportunism in Integrated and Independent Sales Forces," Journal of Economic Behavior and Organization, 9 (5) 247-64.

3. Armstrong, J. Scott and Terry S. Overton (1977), "Estimating Non-Response Bias in Mail Surveys," Journal of Marketing Research 14 (August) 396-402.

4. Barney B. Jay (1986), "Organizational Culture: Can It Be a Source of Sustained Competitive Advantage?" Academy of Management, 11(3) 656-665.

5. Barney B. Jay (1990), "The Debate between Traditional Management Theory and Organizational Economics: Substantive Differences or Intergroup Conflict?" The Academy of Management Review, 15(3) 382-393.

6. Brian Uzzi, (1996), "The sources and consequences of embeddedness for the economic performance of organizations: The network effect” American Sociological Review, Vol. 61 (674-698).

7. Brian Uzzi, (1997), "Social Structure and Competition in Interfirm Networks: The Paradox of Embeddedness" Journal article Administrative Science Quarterly, 42.

8. Brown, James, Dev, Chekitan, \& Lee, Dong-Jin (2000), "Managing Marketing Channel Opportunism: The Efficacy of Alternative Governance Mechanisms", Journal of Marketing, 64 (2) 51-65.

9. Candace Jones, William S. Hesterly and Stephen P. Borgatti (1997), "A General Theory of Network Governance: Exchange Conditions and Social Mechanisms," The Academy of Management Review, 22(4) 911-945.

10. Charles W. L. Hill, (1990), "Cooperation, Opportunism, and the Invisible Hand: Implications for Transaction Cost Theory," Academy of Management Review, 15(3) 500-513.

11. Chao C. Chen, Mike W. Peng, and Patrick A. Saparito (2002), "Individualism, Collectivism, and Opportunism: A Cultural Perspective on Transaction Cost Economics," Journal of Management, 28, 567 583.

12. Chung-Jen Chen and Lien-Sheng Chang, (September 2004), "Dynamics of Business Network Embeddedness" The Journal of American Academy of Business, Cambridge.

13. Deal, T., \& Kennedy, A. E. (1982), “Corporate cultures," Reading, MA: Addison-Wesley.

14. Debi Prasad Mishra, Jan B. Heide and Stanton G. Cort, (1998), "Information Asymmetry and Levels of Agency Relationships," Journal of Marketing Research, 35(3) 277-295.

15. Doney, Patricia M. and Cannon, Joseph P. (1997), "An examination of the nature of trust in buyer-seller relationships," Journal of Marketing, 61(2).

16. Frazier, Gary (1983), "Interorganizational Exchange behaviour in Marketing Channels: A Broadened Perspective," Journal of Marketing, 47, 68-78.

17. Gary L. Frazier (1983), "Interorganizational Exchange Behavior in Marketing Channels: A Broadened Perspective," The Journal of Marketing, 47(4) 68-78. 
18. Gerald R. Salancik and Jeffrey Pfeffer, (Jun., 1978), "A Social Information Processing Approach to Job Attitudes and Task Design," Administrative Science Quarterly, 23(2) 224-253.

19. Ghoshal, Sumantra and Peter Moran (1996), "Bad for Practice: A Critique of the Transaction Cost Framework," Academy of Management Review, 21 (1) 13-47.

20. Gu, Flora, Kineta Hung, \& David Tse (2008), "When Does Guanxi Matter? Issues of Captiatlization and Its Dark Sides," Journal of Marketing, 72, 12-28.

21. Gundlach, T. Gregory and Ravi S. Achrol (1993), "Governance in Exchange: Contract Law and Its Alternatives," Journal of Public Policy and Marketing, 12 (2) 141-155.

22. Heide, Jan B. and George John (1992), "Do Norms Matter in Marketing Relationships?" Journal of Marketing, 56, 32-44.

23. Heide, Jan B. (1994) "Interorganizational Governance in Marketing Channels," Journal of Marketing, 56, 71-85

24. Hill, Charles (1990), "Cooperation, Opportunism, and the Invisible Hand: Implications for Transaction Cost Theory," Academy of Management Review, 15(3) 500-513.

25. Hewett, K. and Bearden, W. (2001), "Dependence, Trust, and Relational Behavior on the Part of Foreign Subsidiary Marketing Operations: Implications for Managing Global Marketing Operations”, Journal of Marketing, 65, 51-66.

26. Hofstede, G. (2001), "Culture's consequences: Comparing values, behaviors, institutions, and organizations across nations," Sage Publications.

27. Hutt, Michael D. and Thomas W. Speh (2000), A Strategic View of Industrial and Organizational Markets, Business Marketing Management, Orlando, FL: Harcourt College Publisher.

28. James R. Brown, Chekitan S. Dev, \& Dong-Jin Lee (2000), "Managing Marketing Channel Opportunism: The Efficacy of Alternative Governance Mechanisms," Journal of Marketing, 64, 51-65.

29. Jan B. Heide, (January 1994) "Interorganizational Governance in Marketing Channels," Journal of Marketing, 56, 71-85.

30. Kumar, Nirmalya, Lisa K. Scheer, and Jan-Benedict E. M. Steenkamp (1995), "The Effect of Perceived Interdependence on Dealer Attitudes," Journal of Marketing Research, 32, 348- 356.

31. Mohr, J and R Spekman(1994), "Partnership attributes, communication behavior, and conflict resolution techniques," Strategic Management Journal.

32. John, George (1984), "An Empirical Investigation of Some Antecedents of Opportunism in a Marketing Channel," Journal of Marketing Research, 21, 278-289.

33. Keith G. Provan and Steven J. Skinner, (1989), "Interorganizational Dependence and Control as Predictors of Opportunism in Dealer-Supplier Relations," The Academy of Management Journal, 32(1) 202-212.

34. Kelly Hewett \& William O. Bearden (2001), "Dependence, Trust, and Relational Behavior on the Part of Foreign Subsidiary Marketing Operations: Implications for Managing Global Marketing Operations," Journal of Marketing, 65, 51-66.

35. Kenneth H. Wathne and Jan B. Heide (2000), "Opportunism in Interfirm Relationships: Forms, Outcomes, and Solutions," Journal of Marketing, 64, 36-51.

36. Mishra, Heide, and Cort (1998), "Information asymmetry and levels of agency relationships" Journal of Marketing Research,35, 277-295.

37. Niels G. Noorderhaven, Carla I. Koen, Sjoerd Beugelsdijk (2002), "Organizational culture and network embeddedness" Tilburg University Center Discussion Paper 2002-91.

38. Nirmalya Kumar, Lisa K. Scheer, and Jan-Benedict E. M. Steenkamp (1995), "The Effects of Perceived Interdependence on Dealer Attitudes," Journal of Marketing Research, 32, 348-356.

39. Provan, Keith G. (1993), "Embeddedness, Interdependence, and Opportunism in Organizational SupplierBuyer Networks," Journal of Management, 19(4) 841.

40. Pete Naudé and Francis Buttle, (2000), “Assessing Relationship Quality,” Industrial Marketing Management, 29(4) 351-361.

41. Peters, T. J., and Waterman, R. H. (1982), "In search of excellence," New York: Harper and Row.

42. Pfeffer, Jeffrey and Gerald R. Salancik (1978), The External Control of Organizations, New York: Harper and Row Publishers Inc.

43. Rangan Kasturi, Raymond Corey, and Frank Cespedes (1993), "Transaction Cost Theory: Inferences from Clinical Field Research on Downstream Vertical Integration”, Organization Science 4(3) 454-477. 
44. Rindfleisch, Aric and Jan B. Heide, (1997), “Transaction Cost Analysis: Past, Present, and Future Applications," Journal of Marketing, 61, 30-54.

45. Sandy D. Jap and Shankar Ganesan (2000), "Control Mechanisms and the Relationship Life Cycle: Implications for Safeguarding Specific Investments and Developing Commitment," Journal of Marketing Research,37, 227-245.

46. Steensma, K and Lyles, MA (2000) "Explaining IJV survival in a transitional economy through social exchange and knowl-edge-based perspectives", Strategic Management Journal, 21(8), 831-852.

47. Stefan Wuyts \& Inge Geyskens (2005), "The Formation of Buyer-Supplier Relationships: Detailed Contract Drafting and Close Partner Selection," Journal of Marketing, 69, 103-117.

48. Sumantra Ghoshal and Peter Moran (1996), "Bad for practice: A critique of the transaction cost theory," Academy of Management Review, 21(1), 13-47.

49. Taran Thune (2007), "University-industry collaboration: the network embeddedness approach" Science and Public Policy, 34(3) 158-168.

50. Triandis, Harry C. (1995), Individualism and Collectivism, Boulder Co; Westview press.

51. Wathne, Kenneth and Jan Heide (2000), "Opportunism in Interfirm Relationships: Forms, Outcomes, and Solutions," Journal of Marketing, 64, 36-51.

52. Williamson, Oliver (1975), Markets and Hierarchies, New York: The Free Press.

53. Williamson, Oliver (1985), The Economic Institutions of Capitalism, New York: Free Press.

54. Williamson, Oliver (1991), "Comparative Economic Organization: The Analysis of Discrete Structural Alternatives," Administrative Science Quality, 36, 269-296.

55. Wuyts, Stefan, and Inge Geyskens (2005), "The Formation of Buyer-Supplier Relationships: Detailed Contracts Drafting and Close Partner Selection," Journal of Marketing, 69, 103-117. 


\section{NOTES}

